Research Article

\title{
Experimental Study on Energy Evolution and Storage Performances of Rock Material under Uniaxial Cyclic Compression
}

\author{
Fengqiang Gong $\mathbb{D},{ }^{1,2,3,4}$ Jingyi Yan $\mathbb{D}^{\mathbb{D}},{ }^{4}$ Yunliang Wang $\mathbb{i D}^{4},{ }^{4}$ and Song Luo $\mathbb{i D}^{4}$ \\ ${ }^{1}$ Engineering Research Center of Safety and Protection of Explosion \& Impact of Ministry of Education (ERCSPEIME), \\ Southeast University, Nanjing 211189, China \\ ${ }^{2}$ School of Civil Engineering, Southeast University, Nanjing 211189, China \\ ${ }^{3}$ Future Underground Space Research Institute, Southeast University, Nanjing 211189, China \\ ${ }^{4}$ School of Resources and Safety Engineering, Central South University, Changsha 410083, China \\ Correspondence should be addressed to Fengqiang Gong; fengqiangg@126.com
}

Received 16 August 2020; Revised 24 September 2020; Accepted 28 September 2020; Published 21 October 2020

Academic Editor: Xianjie Hao

Copyright (c) 2020 Fengqiang Gong et al. This is an open access article distributed under the Creative Commons Attribution License, which permits unrestricted use, distribution, and reproduction in any medium, provided the original work is properly cited.

\begin{abstract}
To investigate the energy evolution and storage performances of rock under uniaxial cyclic compression, a series of uniaxial cyclic loading and unloading compression tests were conducted on Green sandstone and Yueyang granite. Two methods for calculating the total input energy of the specimen under each cycle were proposed. One is based on the actual stress-strain curve of the specimen (ASC method); the other is based on the stress-strain envelope curve during the loading process (SEC method). The experimental results show that, for those two methods, the total input energy, elastic energy, and dissipated energy of the specimen show a quadratic function increasing trend with the increase of stress levels. Besides, the elastic energy increases linearly with the increase of total input energy for both methods, which confirms that the linear energy storage law is also applicable to rock materials under uniaxial cyclic loading and unloading compression conditions. Moreover, the uniaxial compression energy storage coefficient calculated by the SEC method is highly close to that obtained based on the single cycle loading and unloading test, which indicates that the uniaxial compression energy storage coefficient of rock can also be calculated by multiple cyclic loading and unloading test. In conclusion, the linear energy storage law is a basic physical property of rock materials, and the uniaxial compression energy storage coefficient is a physical index reflecting the energy storage capacity of rock materials.
\end{abstract}

\section{Introduction}

As a complex geological material, rocks often exhibited complex deformation and failure performances due to the characteristics of poly mineral composition and inhomogeneous. Studying the deformation and failure performances of rock based on the energy conversion is closely related to the essential features of rock failure, which has been widely recognized [1-4]. Deng et al. found that there is a negative correlation between the rock fragment size and energy dissipation density and proposed a fractal energy consumption model [5]. Bratov and Petrov pointed out that energy consumption in the crack propagation of rock is closely related to the loading magnitude and frequency [6]. Gong et al. investigated the relationship among input energy, elastic energy, and dissipated energy of rocks under tension, compression, and preset angle shear conditions and found the linear energy storage and dissipation laws during the different loading conditions [7-9].

Rock mass in underground engineering is subject to a complex stress environment [10]. Rocks frequently suffer from alternate loading and unloading stress environment due to the influences of blasting, excavation, and other activities. It is necessary to study the performances of rocks under complex stress paths [11]. Cyclic loading and unloading tests at laboratory scale are an effective means to 
study the characteristics of rocks under complex stress paths, and many experimental studies have been carried out [3, 12-19]. Ray et al. explored the changes in uniaxial compressive strength and failure strain of Chunar sandstone versus the number of cycles [16]. Liu et al. developed a damage constitutive model that can reveal the relationship between deformation and strength of rocks under cyclic loading [17]. Geranmayeh-Vaneghi et al. compared the sensitivity of fatigue life and strength degradation effect of rocks to the loading amplitude by a uniaxial cyclic loading test [18]. Liu and He performed triaxial cyclic loading tests under different confining pressures and studied the effects of the cycle number on the axial, volumetric, and transverse strains [19]. In addition, researchers have also conducted cyclic loading tests to investigate the energy evolution performances of rocks. Bagde and Petros analyzed the effect of loading frequency and amplitude on rock energy required to cause fracture by conducting dynamic cyclic loading compression test [20]. Song et al. established the quantitative relationship between the dissipated energy and electromagnetic radiation energy of coal samples during cyclic loading [21]. Based on the loading-unloading tests, Zhang and Gao revealed the variations in the elastic and dissipated energies and the effects of water content on the energy accumulation, energy dissipation, and elastic energy conversion efficiency of rock [22, 23]. Based on uniaxial loadingunloading compression tests, Meng et al. investigated the energy accumulation, dissipation performances, and acoustic emission energy accumulation, dissip during rock deformation and failure [24, 25].

In many aspects of studying the energy performances of rocks, the energy storage characteristics and the peak strength energy are particularly important. For example, Munoz et al. defined a new brittleness index to evaluate rock failure energy accumulation, dissip using the elastic energy at peak strength $[26,27]$. Based on the uniaxial single cyclic loading-unloading compression tests, Gong et al. proposed the energy storage coefficient to evaluate the elastic storage capacity of rocks and presented a new method for calculating the energies of rocks at rock peak strength [28, 29]. However, in some deep engineering sites, it is difficult to obtain enough rock specimens to conduct the uniaxial single cyclic loading-unloading compression test. In order to reduce the number of rock samples needed in the test, we attempted to conduct five levels uniaxial cyclic loading-unloading compression test (for simplicity, it is hereinafter referred to the cyclic loading-unloading test) to replace the uniaxial single cyclic loading-unloading compression test (for simplicity, it is hereinafter referred to as single cyclic loading-unloading test). On this basis, a method for obtaining the energy storage coefficient through the cyclic loading-unloading tests was proposed. In addition, the energy evolution and failure performances of rock induced from the cyclic loading-unloading tests were analyzed and compared with those under single cyclic loading-unloading tests.

\section{Specimen Preparation and Experimental Scheme}

2.1. Specimen Preparation. Rocks used in the tests were Green sandstone and Yueyang granite. In order to avoid repetitive tests, the rock specimens were cored from the same block which has been used in the single cyclic loadingunloading test $[7,8]$. According to the requirements of the test standard, three specimens with the specification approximate $\phi 50 \times 100 \mathrm{~mm}$ were processed for each kind of rock material. The fluctuations of $P$-wave velocity and natural density are very small, which demonstrates that the texture of rock is very homogenous. The appearance and basic parameters of the rock specimens are shown in Figure 1 and Table 1 , respectively.

2.2. Experimental Scheme. The cyclic loading-unloading tests were conducted on INSTRON 1346 testing machine. During the tests, the linear variable differential transformers (LVDTs) were used to get the axial deformation of rock specimens (the total deformation measured by the deformeter minus the deformation of the two pads), and the axial stress were obtained through the pressure sensor of the testing machine. According to the uniaxial compression strength of the rock specimen, the five unloading point were determined, whose unloading stress values corresponded to $0.1 \sigma_{c}, 0.3 \sigma_{c}, 0.5 \sigma_{c}, 0.7 \sigma_{c}$, and $0.9 \sigma_{c}$, respectively. During the tests, the axial stress was loaded to the unloading stress at a rate of $120 \mathrm{kN} / \mathrm{min}$ and then was unloaded. After five loading-unloading processes, the specimen was loaded again until failure occurred. The stress loading path and stressstrain curve in the uniaxial cyclic loading-unloading compression test are presented in Figures 2(a) and 2(b), respectively.

2.3. Calculation Method for Energy Density. The total input energy is converted into elastic energy and dissipated energy during the loading processes of rock [30-32]. Xie et al. revealed the equivalent relationship among input, elastic, and dissipated energies [30]. In cyclic loading-unloading tests, the elastic energy density of rock specimens at different unloading points was obtained by integrating the unloading curves. For total input energy density, we proposed two calculation methods. The calculations of the input energy at the 4 th unloading point and the peak strength point were taken as an example. Approach 1: the total input energy density can be obtained by integrating the practical 4th loading curve and the last loading curve before peak strength. Figure $3(\mathrm{a})$ presents the integral region $\left(S_{1}, S_{2}\right)$ of the total input energy density at the 4 th unloading point and peak strength point. Approach 2: the total input energy can be obtained by integrating the envelope of the loading curve. The integral region of the total input energy densities at the 4th unloading point and peak strength point are 


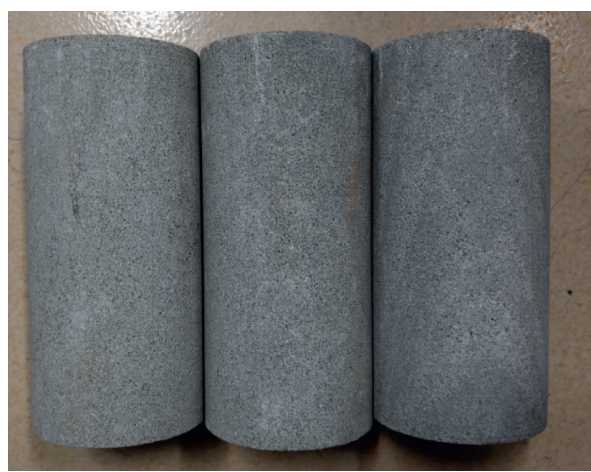

(a)

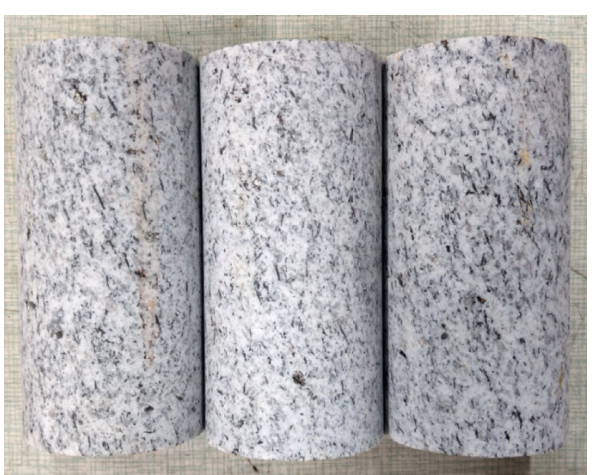

(b)

FIGURE 1: Rock specimens used in the cyclic loading-unloading tests of (a) Green sandstone and (b) Yueyang granite.

TABLE 1: Basis parameters of the tested rock specimens.

\begin{tabular}{|c|c|c|c|c|c|c|c|}
\hline Rock type & Origin & Specimen no. & $D(\mathrm{~mm})$ & $L(\mathrm{~mm})$ & $v(\mathrm{~m} / \mathrm{s})$ & $m(\mathrm{~g})$ & $\rho\left(\mathrm{g} / \mathrm{cm}^{3}\right)$ \\
\hline \multirow{3}{*}{ Green sandstone } & \multirow{3}{*}{ Sichuan Province Zigong city } & GS-1 & 50.55 & 104.92 & 2997.71 & 509 & 2.42 \\
\hline & & GS-2 & 50.46 & 104.06 & 2981.66 & 505 & 2.43 \\
\hline & & GS-3 & 49.00 & 100.50 & 2960.24 & 453 & 2.39 \\
\hline \multirow{3}{*}{ Yueyang granite } & \multirow{3}{*}{ Hunan Province Yueyang city } & YG-1 & 48.86 & 100.46 & 4284.01 & 492 & 2.61 \\
\hline & & YG-2 & 48.90 & 100.56 & 4297.44 & 494 & 2.62 \\
\hline & & YG-3 & 48.90 & 100.52 & 4295.73 & 493 & 2.61 \\
\hline
\end{tabular}

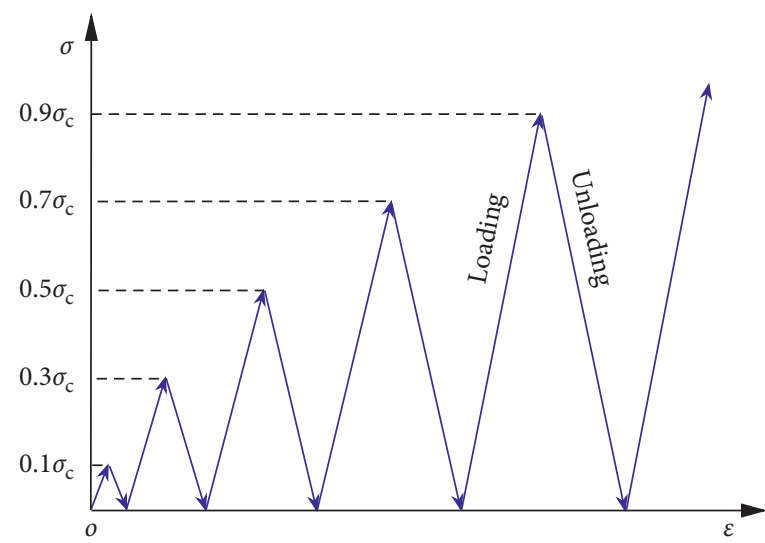

(a)

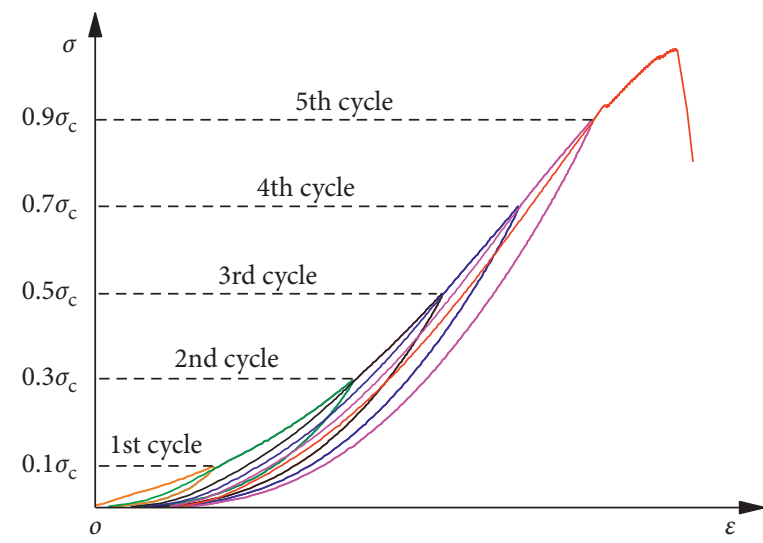

(b)

FIGURE 2: Schematic diagram of rock specimen in cyclic loading-unloading test. (a) Stress loading path (b) Stress-strain curve mode.

$A_{1}+A_{2}+A_{3}+A_{4}$ and $A_{1}+A_{2}+A_{3}+A_{4}+A_{5}+A_{6}$, respectively, as shown in Figure 3(b). The dissipated energy density of the rock specimen is equal to the difference between the total input energy density and elastic energy density.

\section{Experimental Results}

3.1. Stress-Strain Characteristics. Figure 4 shows the stressstrain curves of the rock specimens under cyclic loadingunloading compression. The peak compressive stress of Green sandstone and Yueyang granite specimens are 90.04 MPa, 102.63 MPa, 100.54 MPa and 210.07 $\mathrm{MPa}$, 220.78 $\mathrm{MPa}, 212.90 \mathrm{MPa}$, respectively, with the average values of $97.74 \mathrm{MPa}$ and $214.58 \mathrm{MPa}$, respectively. The maximum axial strain of Green sandstone and Yueyang granite specimens are 0.0092, 0.0090, 0.0099 and 0.0072, $0.0070,0.0070$, respectively. The peak compressive strength of Yueyang granite is obviously higher than that of Green sandstone, and its maximum axial strain is lower than that of Green sandstone. In literature [28], the stress-strain characteristics of Green sandstone and Yueyang granite under single cyclic loading-unloading compression were given (Figure 5). It can be seen that the maximum axial strains of rock materials are approximately equivalent under the two test conditions. Moreover, the average peak compression strength of Green sandstone is $99.83 \mathrm{MPa}$ in the single cyclic 


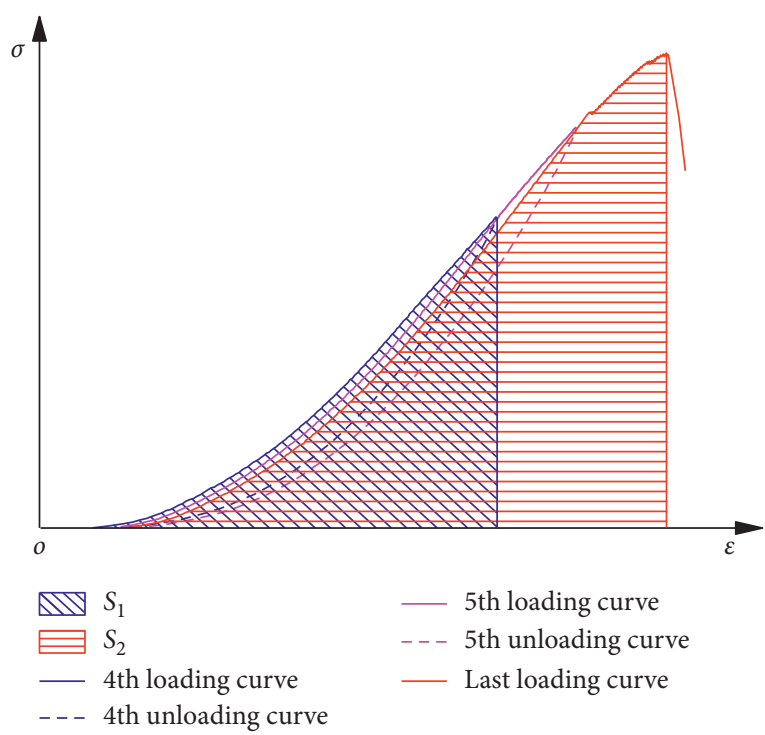

(a)

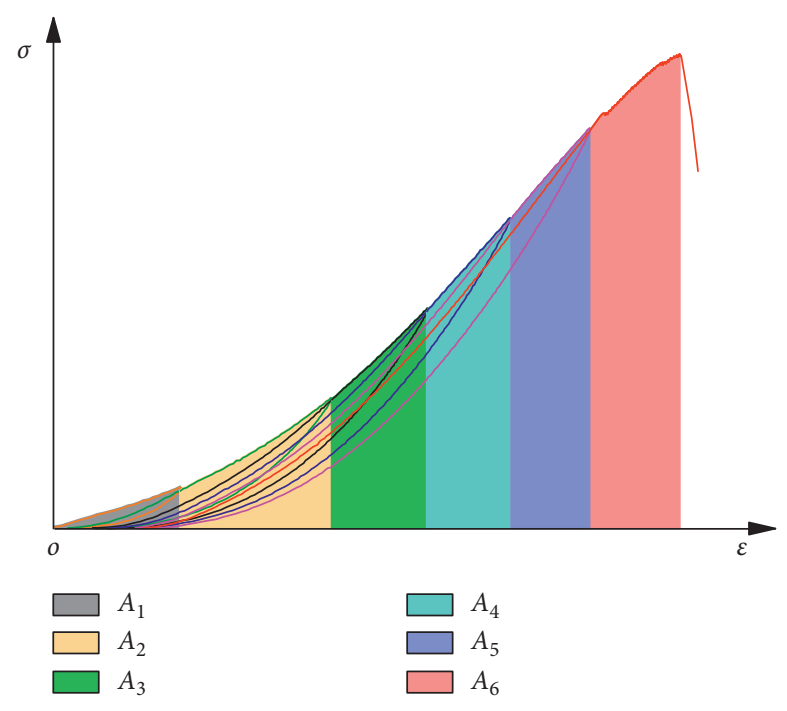

(b)

FIGURE 3: Schematic diagram for calculating input energy density in cyclic loading-unloading test. (a) Approach 1. (b) Approach 2.

loading-unloading tests. Compared with the cyclic loadingunloading test, the change of peak strength is very small. However, the peak strength of Yueyang granite is obviously increased in the cyclic loading-unloading test, which is $9.3 \%$ higher than $196.37 \mathrm{MPa}$ in the single cyclic loadingunloading test.

\subsection{Relationship between Energy Density and Stress Levels.} The energy density values of the rock specimens at different unloading points obtained by the two calculation approaches are listed in Table 2. Based on the data in Table 2 and literature [28], the variation curves of total input and elastic energy densities with the stress level (the ratio of unloading stress to peak strength) in the cyclic loadingunloading tests and single cyclic loading-unloading test are plotted in Figures 6-8. From Figures 6 and 7, it can be seen that the total input energy density of both rock materials increases nonlinearly with the increase of stress level in the cyclic loading-unloading test, whether calculated by approach 1 or 2 . The variation law of total input energy density under such test condition is very similar to that in the single loading-unloading test. Similarly, Figure 8 shows that the elastic energy density also increases nonlinearly with the increase of stress level. By means of nonlinear fitting, the fitted functions between the total input and elastic energy densities and the stress level were obtained and are listed in Table 3. It can be seen that all the values of correlation coefficient $R^{2}$ are larger than 0.9990 , indicating that the obtained fitted functions are reliable. Moreover, the dissipated energy density can be obtained by simply subtracting the elastic energy density from the total input energy density.

3.3. Relationship between the Elastic Energy and Total Input Energy Density. According to the data in Table 2, we further studied the relationship between energy densities of rock specimens under cyclic loading-unloading conditions. Figures 9 and 10 show that the elastic energy density of both rock materials increases linearly with the increase of the total input energy density, which is irrelevant to the calculation methods of total input energy density. Table 4 presents the fitted functions between the elastic energy density and total input energy density, which are in a form of $u_{e}^{i}=a u^{i}+b$. It can be considered that there is a strong linear relationship between the two energy densities, with correlation coefficient $R^{2}$ values greater than 0.99 . The fitted functions between the dissipated density and the total input energy density can be obtained by combining the formula $u_{e}^{i}+u_{d}^{i}=u^{i}$, which can be expressed by $u_{e}^{i}=(1-a) u^{i}-b$. In addition, the relationship between dissipative energy and total input energy is also linear, which has been confirmed in previous studies [7-9, 28, 33].

To evaluate the ability of storing elastic energy of rock materials during a compression test, the energy storage coefficient (ESC) and energy dissipation coefficient (EDC) were proposed by Gong et al. [7, 8]. The ESCs of Green sandstone and Yueyang granite obtained by the single cyclic loading-unloading test were 0.7234 and 0.8726 , respectively. The values of ESC obtained from cyclic loading-unloading tests are listed in Table 5. For Green sandstone, the deviations of ESC calculated by approaches 1 and 2 with that obtained by single cyclic loading-unloading test are $8.16 \%$ and $4.81 \%$, respectively. For Yueyang granite, the deviations of ESC are $3.94 \%$ and $0.61 \%$, respectively. It can be seen that the ESC of both rock materials calculated by the approach 2 in cyclic loading-unloading test is closer to that obtained by the single cyclic loading-unloading test.

3.4. Calculation of Energy Density at the Peak Strength. It is mentioned in literature $[8,28]$ that the peak elastic energy density (elastic energy density at the peak strength) of 


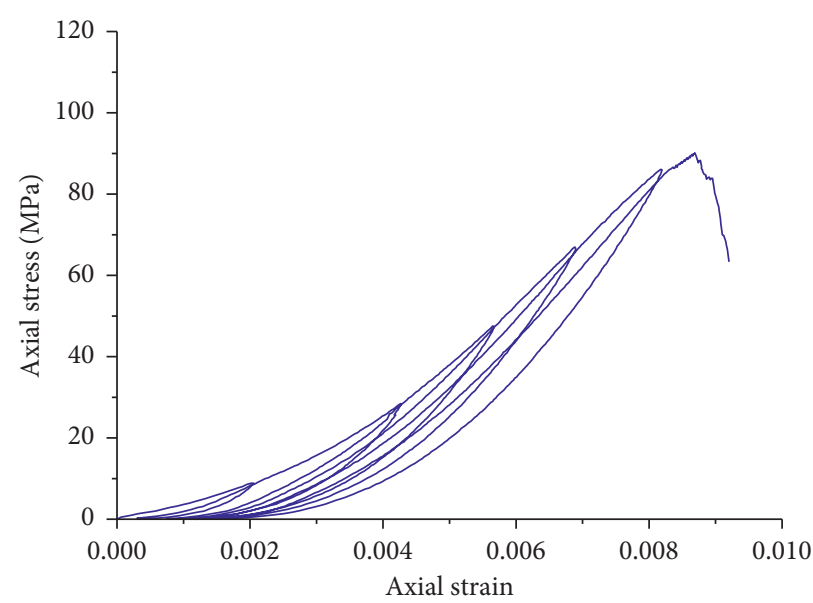

GS-1

(a)

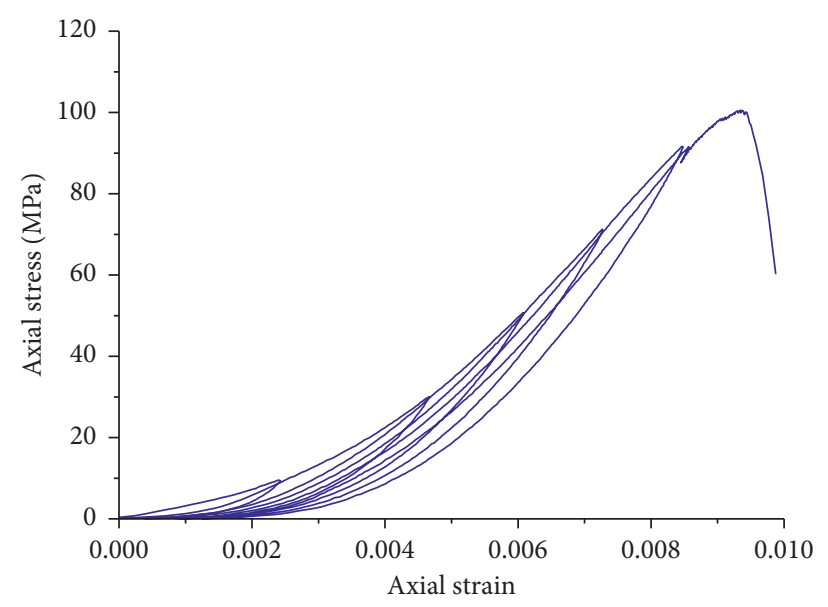

_ GS-3

(c)

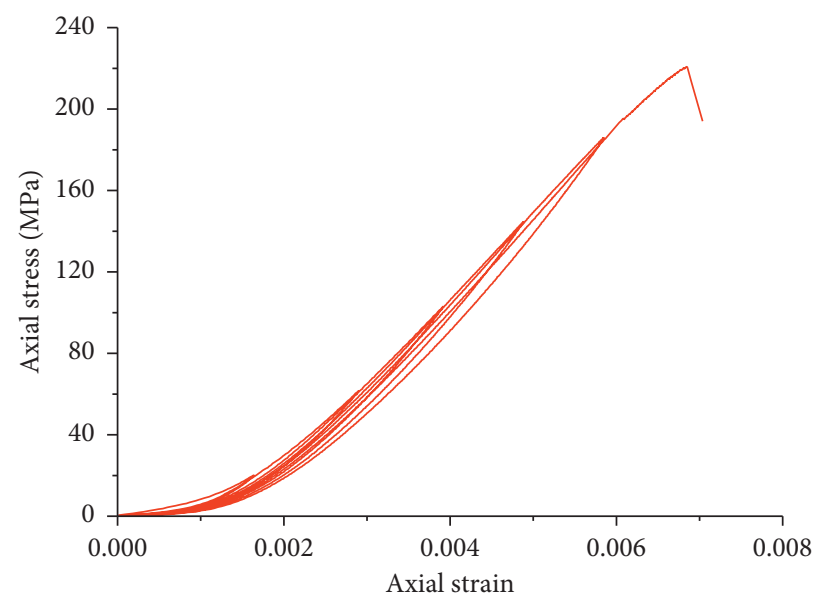

- YG-2

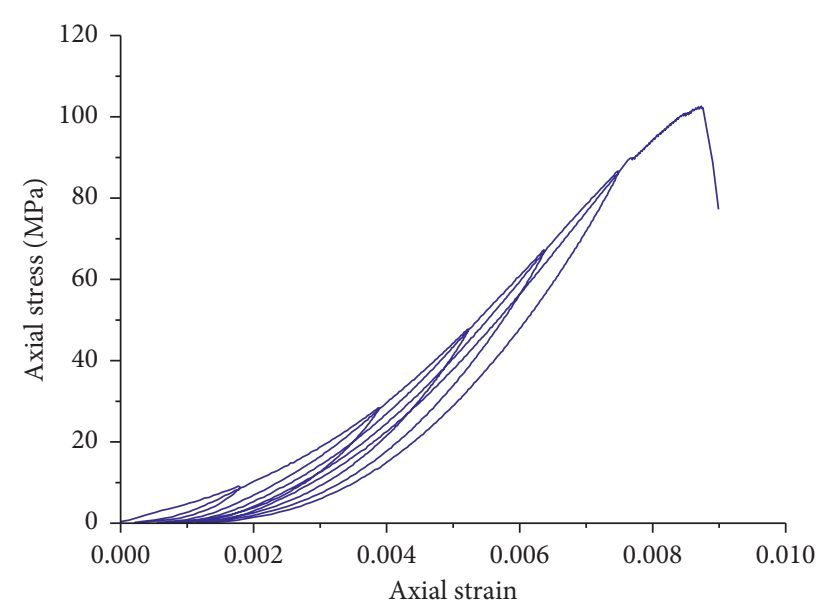

— GS-2

(b)

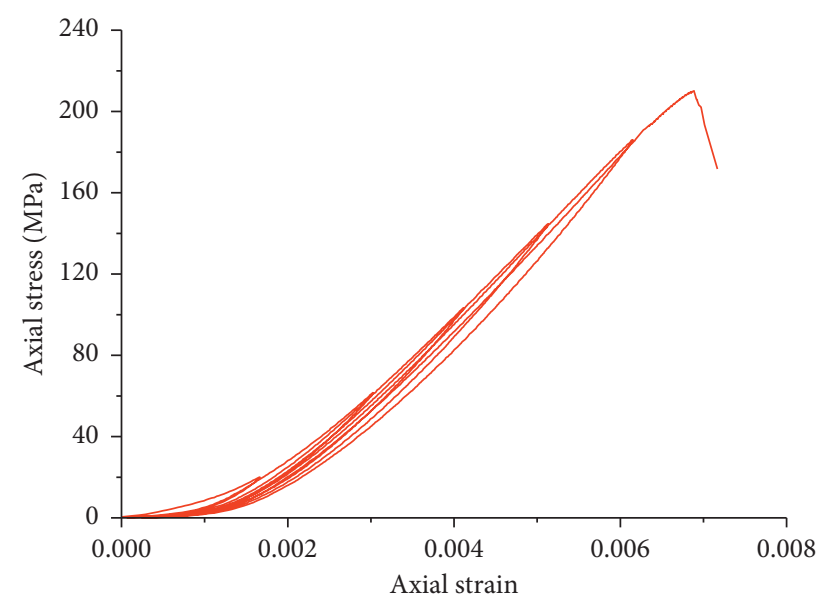

— YG-1

(d)

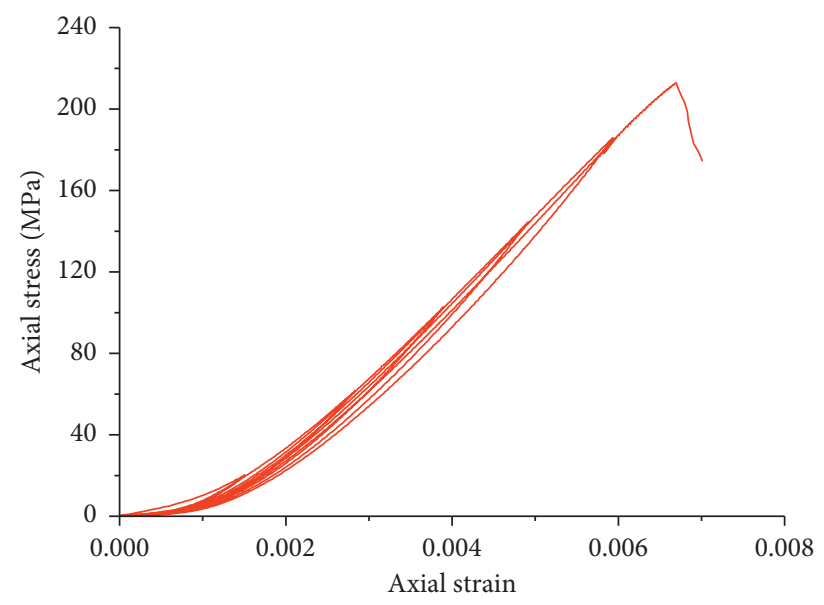

- YG-3

(e)

(f)

FIGURE 4: Stress-strain curve of the rock specimen in cyclic loading-unloading tests. (a) GS-1; (b) GS-2; (c) GS-3; (d) YG-1; (e) YG-2; (f) YG-3. 


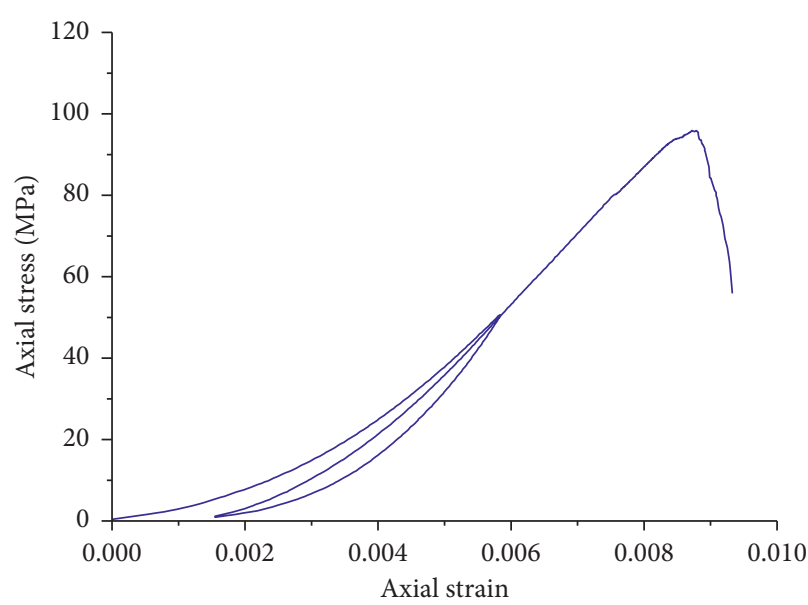

- Green sandstone

(a)

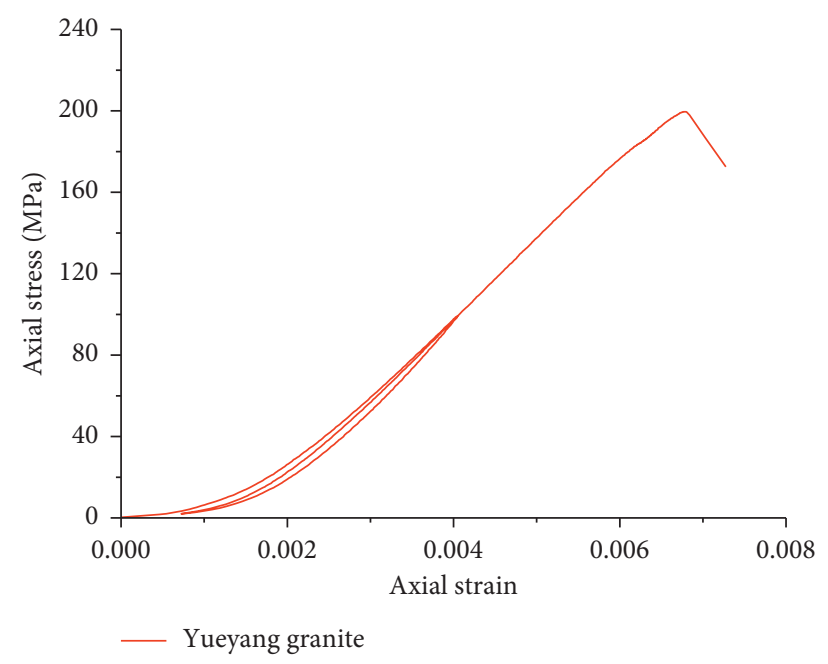

(b)

FIgURE 5: Stress-strain curve of the rock specimens in the single cyclic loading-unloading test at a setting stress level of 0.5 [7]. (a) Green sandstone; (b) Yueyang granite.

TABLE 2: Testing parameters at the unloading point.

\begin{tabular}{|c|c|c|c|c|c|c|c|c|}
\hline \multirow{2}{*}{$\begin{array}{l}\text { Specimen } \\
\text { no. }\end{array}$} & \multirow{2}{*}{$\begin{array}{l}\text { Unloading } \\
\text { step }\end{array}$} & \multirow{2}{*}{$\begin{array}{l}\text { Unloading stress } \\
\qquad(\mathrm{MPa})\end{array}$} & \multirow{2}{*}{$\begin{array}{l}\text { Unloading stress } \\
\text { level } i\end{array}$} & \multicolumn{2}{|c|}{$u^{i}\left(\mathrm{~mJ} \cdot \mathrm{mm}^{-3}\right)$} & \multirow{2}{*}{$\begin{array}{c}u_{e}^{i} \\
\left(\mathrm{~mJ} \cdot \mathrm{mm}^{-3}\right)\end{array}$} & \multicolumn{2}{|c|}{$u_{d}^{i}\left(\mathrm{~mJ} \cdot \mathrm{mm}^{-3}\right)$} \\
\hline & & & & $\begin{array}{c}\text { Approach } \\
1\end{array}$ & $\begin{array}{c}\text { Approach } \\
2\end{array}$ & & $\begin{array}{c}\text { Approach } \\
1\end{array}$ & $\begin{array}{c}\text { Approach } \\
2\end{array}$ \\
\hline \multirow{5}{*}{ GS-1 } & 1 st & 8.88 & 0.10 & 0.0081 & 0.0081 & 0.0043 & 0.0038 & 0.0038 \\
\hline & $2 \mathrm{nd}$ & 28.46 & 0.32 & 0.0447 & 0.0473 & 0.0265 & 0.0182 & 0.0208 \\
\hline & $3 \mathrm{rd}$ & 47.54 & 0.53 & 0.0863 & 0.0992 & 0.0621 & 0.0242 & 0.0371 \\
\hline & 4th & 66.95 & 0.74 & 0.1482 & 0.1695 & 0.1119 & 0.0363 & 0.0576 \\
\hline & 5 th & 86.08 & 0.96 & 0.2339 & 0.2682 & 0.1760 & 0.0579 & 0.0922 \\
\hline \multirow{5}{*}{ GS-2 } & $1 \mathrm{st}$ & 9.14 & 0.09 & 0.0078 & 0.0078 & 0.0041 & 0.0037 & 0.0037 \\
\hline & $2 \mathrm{nd}$ & 28.39 & 0.28 & 0.0418 & 0.0445 & 0.0270 & 0.0148 & 0.0175 \\
\hline & $3 \mathrm{rd}$ & 47.71 & 0.46 & 0.0844 & 0.0948 & 0.0623 & 0.0221 & 0.0325 \\
\hline & 4 th & 67.22 & 0.65 & 0.1428 & 0.1608 & 0.1100 & 0.0328 & 0.0508 \\
\hline & 5th & 86.61 & 0.84 & 0.2182 & 0.2459 & 0.1709 & 0.0473 & 0.0750 \\
\hline \multirow{5}{*}{ GS-3 } & 1 st & 9.53 & 0.09 & 0.0100 & 0.0100 & 0.0048 & 0.0052 & 0.0052 \\
\hline & $2 \mathrm{nd}$ & 30.10 & 0.30 & 0.0484 & 0.0519 & 0.0309 & 0.0175 & 0.0210 \\
\hline & $3 \mathrm{rd}$ & 50.74 & 0.50 & 0.0972 & 0.1083 & 0.0716 & 0.0256 & 0.0367 \\
\hline & 4 th & 71.21 & 0.71 & 0.1614 & 0.1807 & 0.1248 & 0.0366 & 0.0559 \\
\hline & 5 th & 91.64 & 0.91 & 0.2476 & 0.2779 & 0.1938 & 0.0538 & 0.0841 \\
\hline \multirow{5}{*}{ YG-1 } & $1 \mathrm{st}$ & 20.04 & 0.10 & 0.0129 & 0.0129 & 0.0088 & 0.0041 & 0.0041 \\
\hline & $2 \mathrm{nd}$ & 61.63 & 0.29 & 0.0624 & 0.0660 & 0.0533 & 0.0091 & 0.0127 \\
\hline & $3 \mathrm{rd}$ & 103.30 & 0.49 & 0.1466 & 0.1554 & 0.1302 & 0.0164 & 0.0252 \\
\hline & 4th & 144.72 & 0.69 & 0.2665 & 0.2812 & 0.2403 & 0.0262 & 0.0409 \\
\hline & 5th & 186.10 & 0.89 & 0.4258 & 0.4483 & 0.3837 & 0.0421 & 0.0646 \\
\hline \multirow{5}{*}{ YG-2 } & $1 \mathrm{st}$ & 20.05 & 0.09 & 0.0123 & 0.0123 & 0.0091 & 0.0032 & 0.0032 \\
\hline & 2nd & 61.63 & 0.28 & 0.0591 & 0.0618 & 0.0515 & 0.0076 & 0.0103 \\
\hline & $3 \mathrm{rd}$ & 102.92 & 0.47 & 0.1386 & 0.1451 & 0.1241 & 0.0145 & 0.0210 \\
\hline & 4th & 144.54 & 0.65 & 0.2524 & 0.2637 & 0.2281 & 0.0243 & 0.0356 \\
\hline & 5th & 185.84 & 0.84 & 0.4061 & 0.4240 & 0.3650 & 0.0411 & 0.0590 \\
\hline \multirow{5}{*}{ YG-3 } & $1 \mathrm{st}$ & 20.25 & 0.10 & 0.0121 & 0.0121 & 0.0088 & 0.0033 & 0.0033 \\
\hline & $2 \mathrm{nd}$ & 61.69 & 0.29 & 0.0621 & 0.0647 & 0.0545 & 0.0076 & 0.0102 \\
\hline & $3 \mathrm{rd}$ & 102.92 & 0.48 & 0.1455 & 0.1518 & 0.1319 & 0.0136 & 0.0199 \\
\hline & 4 th & 144.52 & 0.68 & 0.2673 & 0.2777 & 0.2435 & 0.0238 & 0.0342 \\
\hline & 5th & 185.88 & 0.87 & 0.4284 & 0.4450 & 0.3889 & 0.0395 & 0.0561 \\
\hline
\end{tabular}

$u^{i}, u_{e}^{i}$, and $u_{d}^{i}$ are the total input energy density, elastic energy density, and dissipated energy density of rock specimen under different unloading stress levels $i$. 


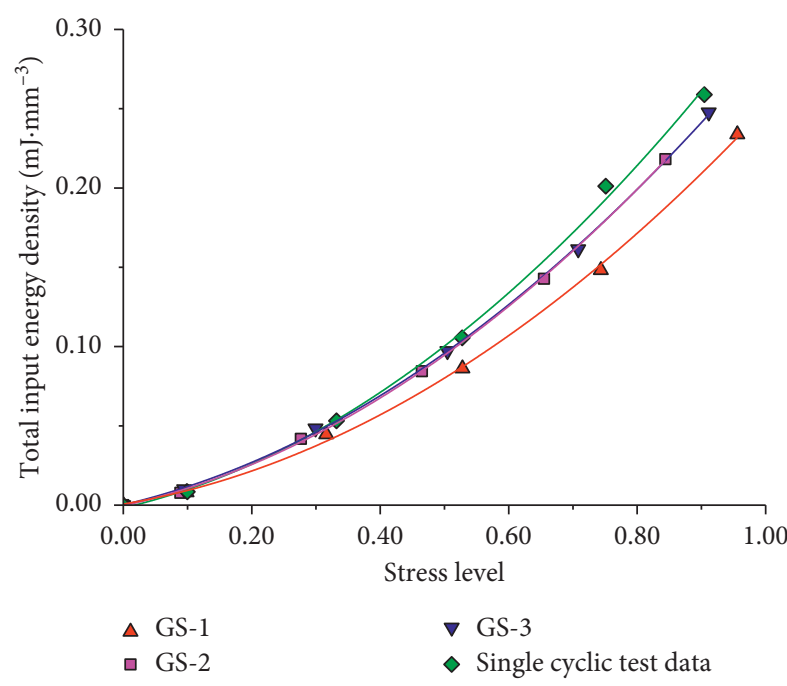

(a)

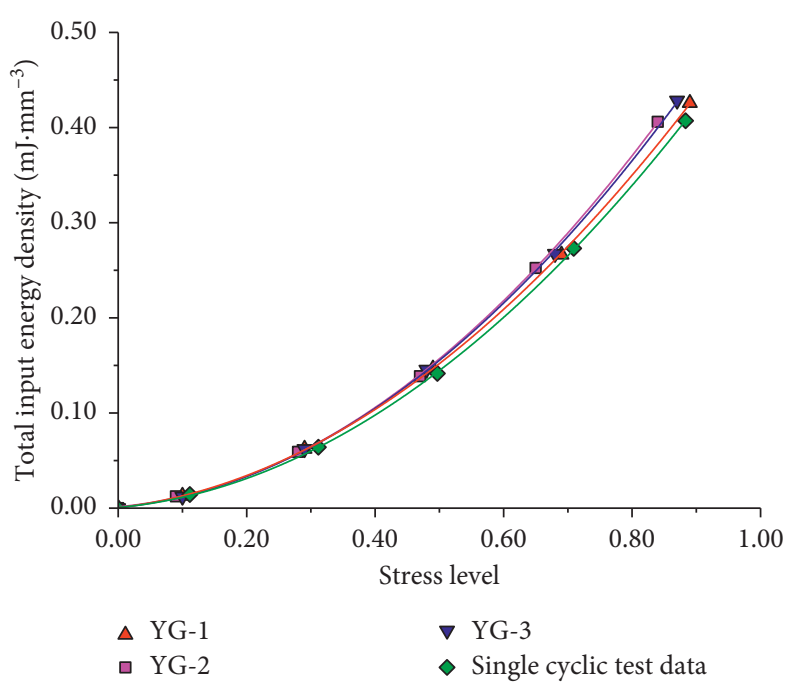

(b)

FIGURE 6: Variation tendency of the total input energy density with the stress levels in approach 1. (a) Green sandstone; (b) Yueyang granite.

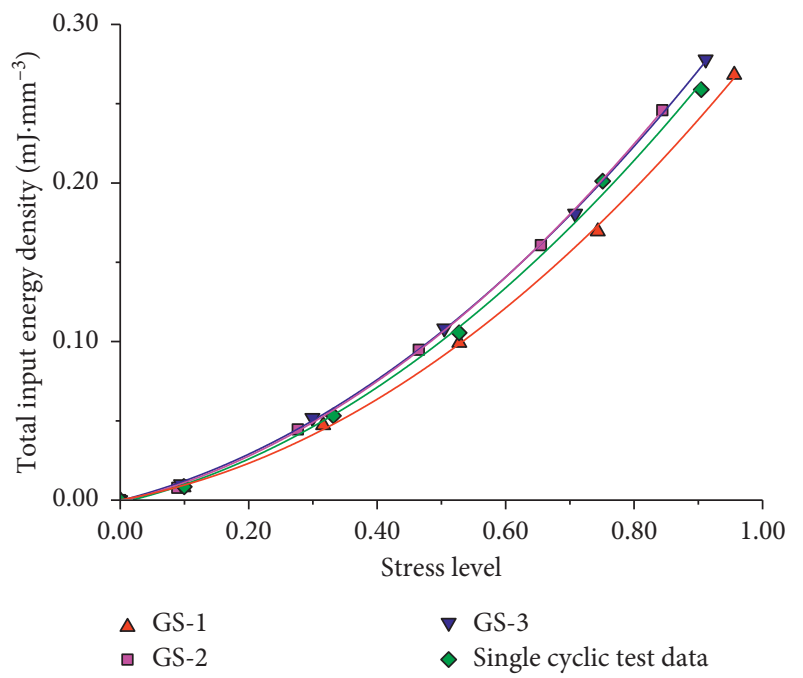

(a)

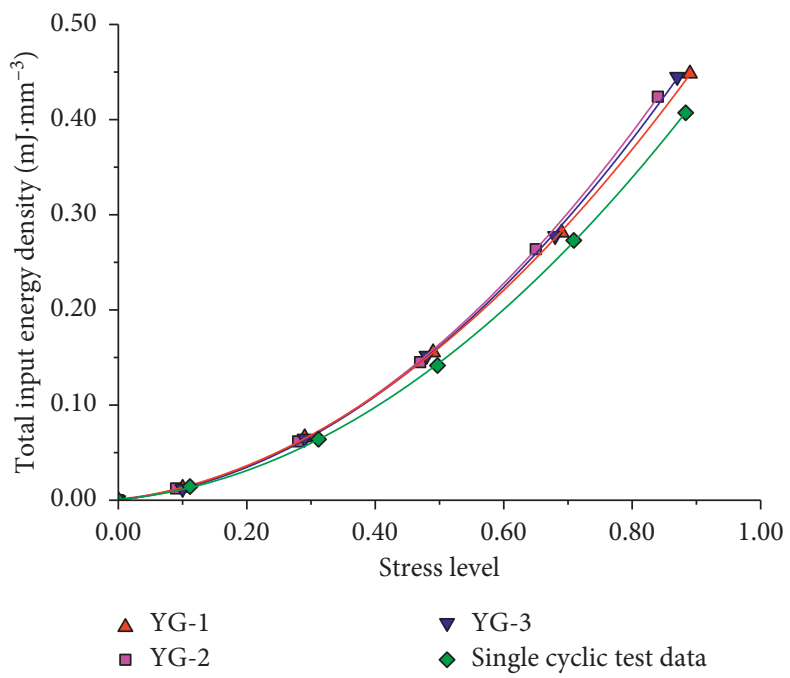

(b)

FIGURE 7: Variation tendency of total input energy density with the stress levels in approach 2. (a) Green sandstone; (b) Yueyang granite.

rock can be calculated by the fitted functions between the elastic energy density and total input energy density. The peak dissipated energy density (dissipated energy density at the peak strength) of rock can be obtained by the fitted functions between the dissipated energy density and total input energy density or by the difference between the total input energy density and elastic energy density. Section 2.3 presents two integral methods for calculating the peak total input energy density (total input energy density at the peak strength) of rock. Table 6 gives the results of the peak energy density of the rock specimens. In the single cyclic loading-unloading tests, the peak total input, elastic, and dissipated energy densities of Green sandstone are $0.3441 \mathrm{~mJ} / \mathrm{mm}^{3}, 0.2473 \mathrm{~mJ} / \mathrm{mm}^{3}$, and $0.0968 \mathrm{~mJ} / \mathrm{mm}^{3}$, respectively. These three parameters of Yueyang granite are $0.5377 \mathrm{~mJ} / \mathrm{mm}^{3}, 0.4677 \mathrm{~mJ} / \mathrm{mm}^{3}$, and $0.0700 \mathrm{~mJ} / \mathrm{mm}^{3}$, respectively [7]. According to the average energy density of the rock specimens listed in Table 6, it can be seen that the peak energy density of Green sandstone calculated by approach 2 in the cyclic loading-unloading test are closer to that obtained by the single cyclic loading-unloading test. For Yueyang granite, the peak energy density results obtained by approach 1 are more approximate to the results from single cyclic loading-unloading test. From the integral approaches, we can see that the peak total input energy density calculated by approach 1 refers to the actual input energy from outside into per unit volume of the rock during the last loading. The peak elastic energy density represents the internal elastic energy stored in per unit volume of rock at the peak strength. The integral 


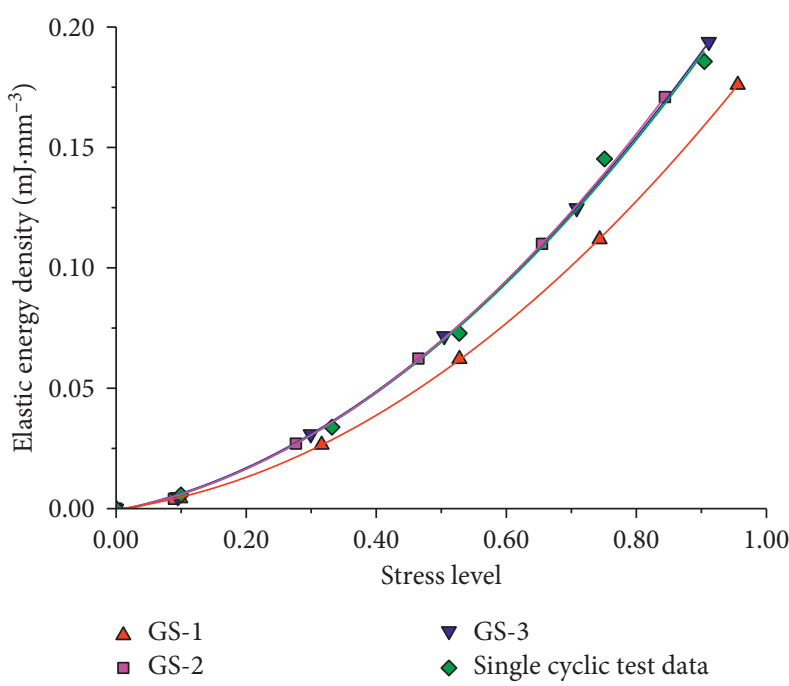

(a)

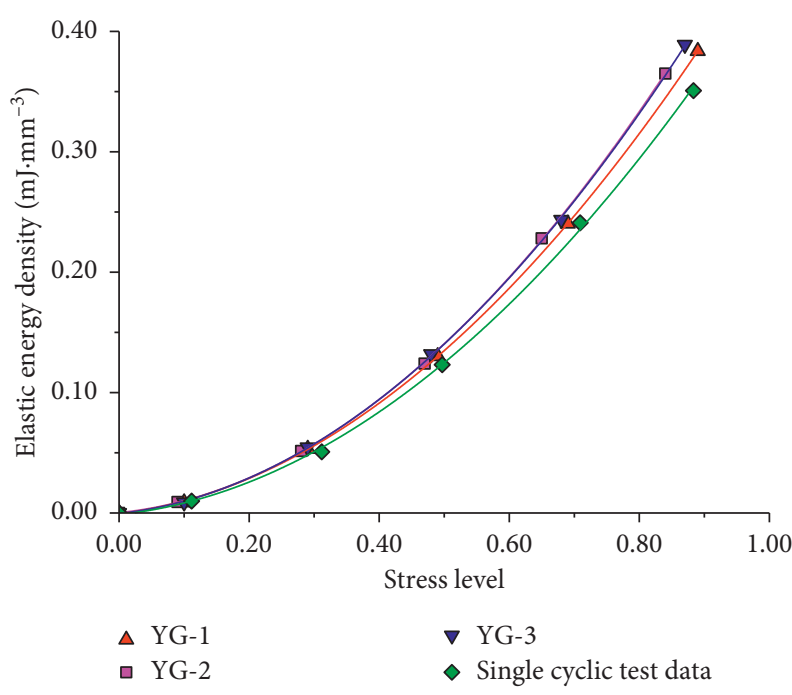

(b)

FIgURE 8: Variation tendency of the elastic energy density with the stress levels. (a) Green sandstone; (b) Yueyang granite.

TABLE 3: Fitted functions between the energy density and stress level.

\begin{tabular}{llll}
\hline Specimen no. & \multicolumn{1}{c}{ Approach 1} & $u^{i}$ and $i$ & Approach 2 \\
& & \multicolumn{1}{c}{$u_{e}^{i}$ and $i$} \\
GS-1 & $u^{i}=0.1819 i^{2}+0.0680 i+0.0007$ & $u^{i}=0.2155 i^{2}+0.0726 i+0.0001$ & $u_{e}^{i}=0.1559 i^{2}+0.0352 i-0.0003$ \\
& $\left(R^{2}=0.9991\right)$ & $\left(R^{2}=0.9995\right)$ & $\left(R^{2}=1\right)$ \\
GS-2 & $u^{i}=0.1986 i^{2}+0.0906 i-0.0004$ & $u^{i}=0.2307 i^{2}+0.0975 i-0.0010$ & $u_{e}^{i}=0.1819 i^{2}+0.0501 i-0.0008$ \\
& $\left(R^{2}=0.9998\right)$ & $\left(R^{2}=0.9999\right)$ & $\left(R^{2}=0.9999\right)$ \\
GS-3 & $u^{i}=0.1915 i^{2}+0.0955 i+0.0002$ & $u^{i}=0.2216 i^{2}+0.1020 i-0.0003$ & $u_{e}^{i}=0.1757 i^{2}+0.0534 i-0.0008$ \\
& $\left(R^{2}=0.9997\right)$ & $\left(R^{2}=0.9998\right)$ & $\left(R^{2}=0.9999\right)$ \\
YG-1 & $u^{i}=0.4617 i^{2}+0.07694 i+0.001$ & $u^{i}=0.4816 i^{2}+0.0776 i+0.0007$ & $u_{e}^{i}=0.4261 i^{2}+0.0557 i-0.0001$ \\
& $\left(R^{2}=1\right)$ & $\left(R^{2}=1\right)$ & $\left(R^{2}=1\right)$ \\
YG-2 & $u^{i}=0.4926 i^{2}+0.0647 i+0.0013$ & $u^{i}=0.5126 i^{2}+0.0694 i+0.0011$ & $u_{e}^{i}=0.4459 i^{2}+0.0575 i+0.0002$ \\
& $\left(R^{2}=0.9999\right)$ & $\left(R^{2}=0.9999\right)$ & $\left(R^{2}=1\right)$ \\
YG-3 & $u^{i}=0.4838 i^{2}+0.0662 i+0.0009$ & $u^{i}=0.5003 i^{2}+0.0710 i+0.0007$ & $u_{e}^{i}=0.4425 i^{2}+0.0592 i-0.0002$ \\
& $\left(R^{2}=1\right)$ & $\left(R^{2}=1\right)$ & $\left(R^{2}=1\right)$ \\
\hline
\end{tabular}

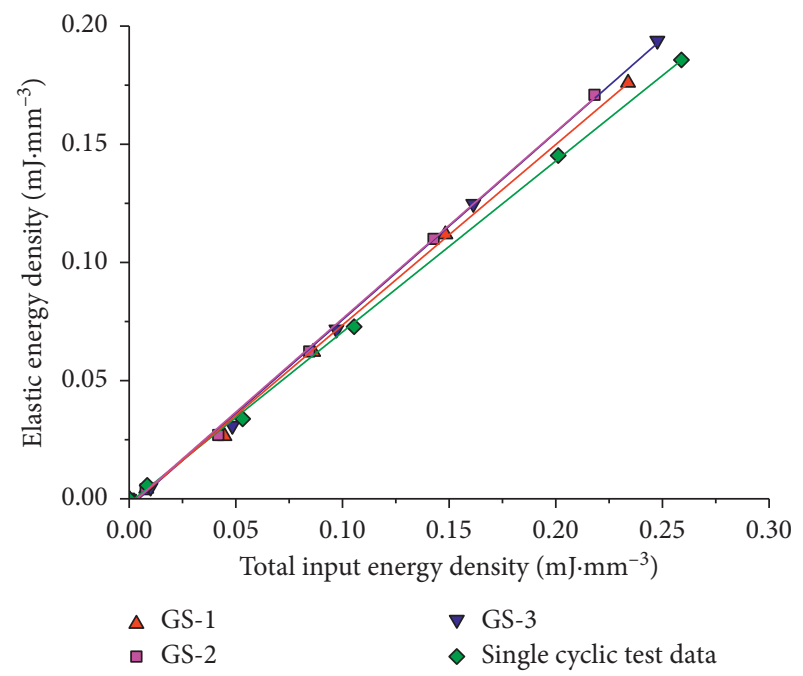

(a)



(b)

FIGURE 9: Relationship between the elastic and total input energy density of rock specimens in approach 1. (a) Green sandstone; (b) Yueyang granite. 


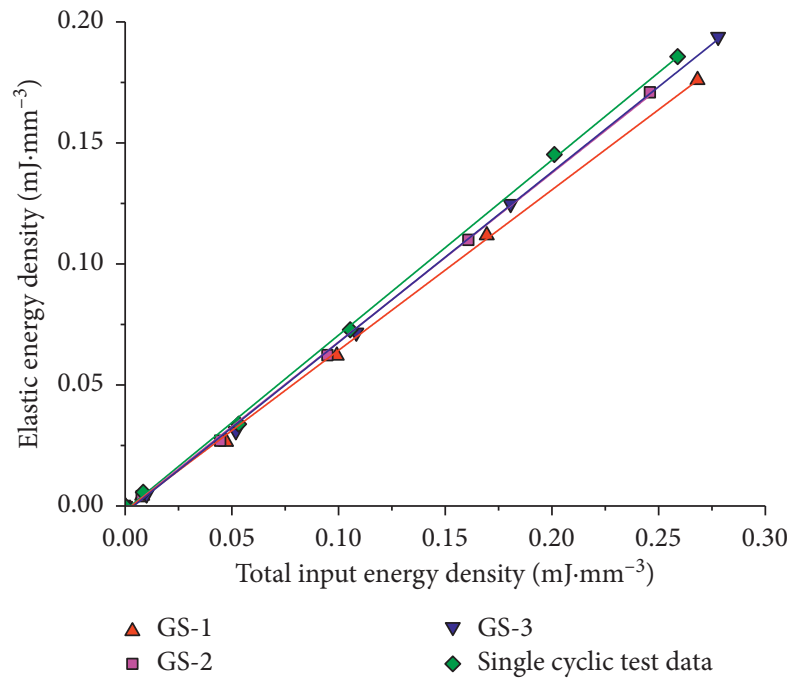

(a)

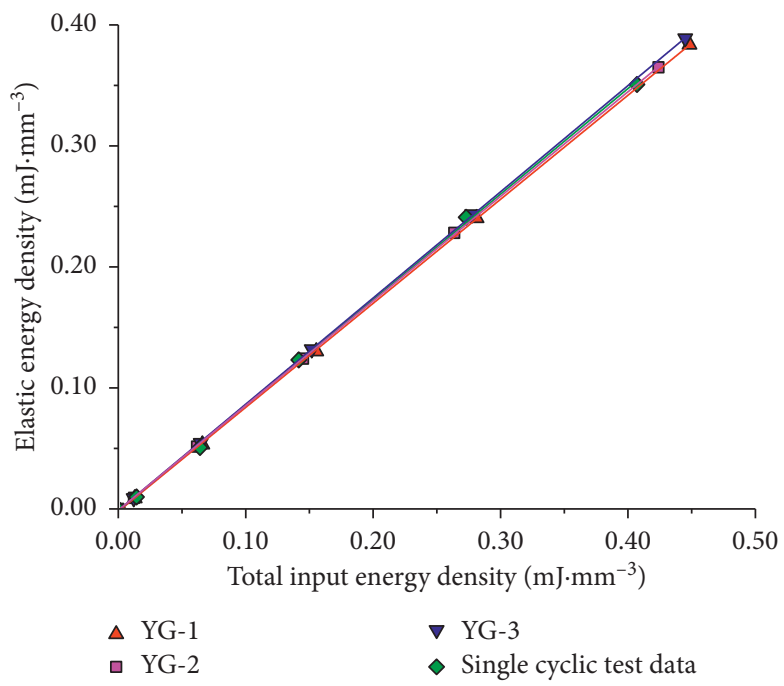

(b)

FIGURE 10: Relationship between the elastic and total input energy density of rock specimens in approach 2. (a) Green sandstone; (b) Yueyang granite.

TABLE 4: Fitted functions between the elastic energy density and total input energy density.

Specimen no.

\begin{tabular}{lc} 
& Approach 1 \\
\hline GS-1 & $u_{e}^{i}=0.7638 u^{i}-0.0029\left(R^{2}=0.9985\right)$ \\
GS-2 & $u_{e}^{i}=0.7907 u^{i}-0.0029\left(R^{2}=0.9990\right)$ \\
GS-3 & $u_{e}^{i}=0.7928 u^{i}-0.0036\left(R^{2}=0.9989\right)$ \\
YG-1 & $u_{e}^{i}=0.9060 u^{i}-0.0020\left(R^{2}=0.9999\right)$ \\
YG-2 & $u_{e}^{i}=0.9030 u^{i}-0.0011\left(R^{2}=1\right)$ \\
YG-3 & $u_{e}^{i}=0.9120 u^{i}-0.0012\left(R^{2}=1\right)$ \\
\hline
\end{tabular}

Approach 2

$$
\begin{gathered}
u_{e}^{i}=0.6630 u^{i}-0.0020\left(R^{2}=0.9992\right) \\
u_{e}^{i}=0.6987 u^{i}-0.0021\left(R^{2}=0.9994\right) \\
u_{e}^{i}=0.7041 u^{i}-0.0028\left(R^{2}=0.9993\right) \\
u_{e}^{i}=0.8599 u^{i}-0.0021\left(R^{2}=0.9999\right) \\
u_{e}^{i}=0.8643 u^{i}-0.0010\left(R^{2}=1\right) \\
u_{e}^{i}=0.8776 u^{i}-0.0012\left(R^{2}=1\right)
\end{gathered}
$$

\begin{tabular}{|c|c|c|c|c|c|c|}
\hline \multirow[t]{2}{*}{ Specimen no. } & \multicolumn{2}{|c|}{$\begin{array}{l}\text { Total input energy density } \\
\left(\mathrm{mJ} / \mathrm{mm}^{3}\right)\end{array}$} & \multicolumn{2}{|c|}{$\begin{array}{l}\text { Peak elastic energy density } \\
\qquad\left(\mathrm{mJ} / \mathrm{mm}^{3}\right)\end{array}$} & \multicolumn{2}{|c|}{$\begin{array}{l}\text { Peak dissipated energy density } \\
\qquad\left(\mathrm{mJ} / \mathrm{mm}^{3}\right)\end{array}$} \\
\hline & Approach 1 & Approach 2 & Approach 1 & Approach 2 & Approach 1 & Approach 2 \\
\hline GS-1 & 0.2556 & 0.3129 & 0.1923 & 0.2054 & 0.0633 & 0.1075 \\
\hline GS-2 & 0.3258 & 0.3659 & 0.2547 & 0.2535 & 0.0711 & 0.1124 \\
\hline GS-3 & 0.3129 & 0.3623 & 0.2444 & 0.2523 & 0.0685 & 0.1100 \\
\hline Average & 0.2981 & 0.3470 & 0.2305 & 0.2371 & 0.0676 & 0.1100 \\
\hline YG-1 & 0.5587 & 0.5950 & 0.5042 & 0.5096 & 0.0545 & 0.0854 \\
\hline YG-2 & 0.5970 & 0.6266 & 0.5379 & 0.5406 & 0.0591 & 0.0860 \\
\hline YG-3 & 0.5682 & 0.5968 & 0.5051 & 0.5226 & 0.0631 & 0.0742 \\
\hline Average & 0.5746 & 0.6061 & 0.5157 & 0.5243 & 0.0589 & 0.0819 \\
\hline
\end{tabular}

TABLE 5: Calculation results of ESC with two approaches.

\begin{tabular}{lccccc}
\hline Specimen no. & ESC & & Specimen no. & Approach 1 & Approach 2 \\
\hline GS-1 & Approach 1 & Approach 2 & YG-1 & 0.9060 & 0.8599 \\
GS-2 & 0.7638 & 0.6630 & YG-2 & 0.9030 & 0.8643 \\
GS-3 & 0.7907 & 0.6987 & YG-3 & 0.9120 & 0.8776 \\
Average & 0.7928 & 0.7041 & Average & 0.9070 & 0.8673 \\
\hline
\end{tabular}

TABLE 6: Calculation results of peak energy density of rock. 

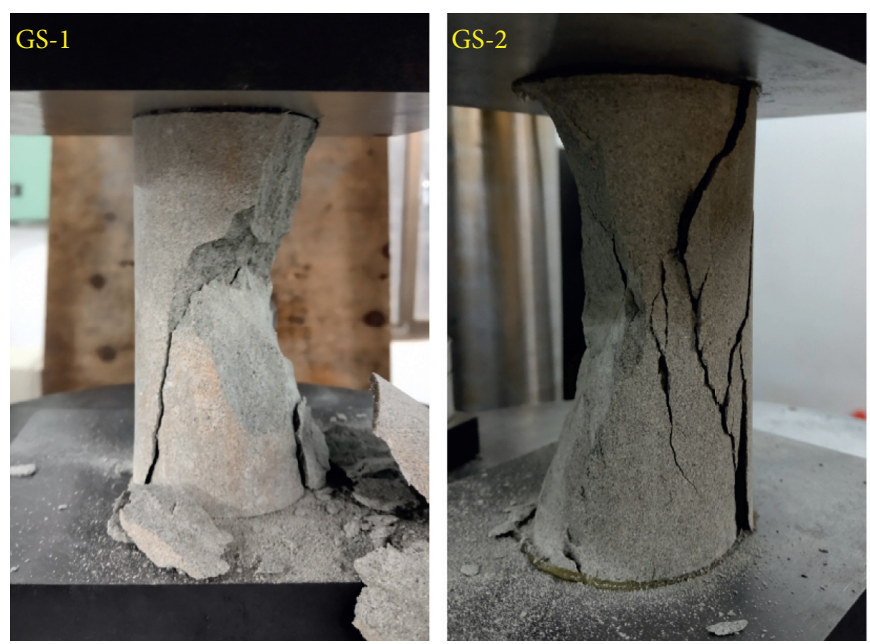

(a)
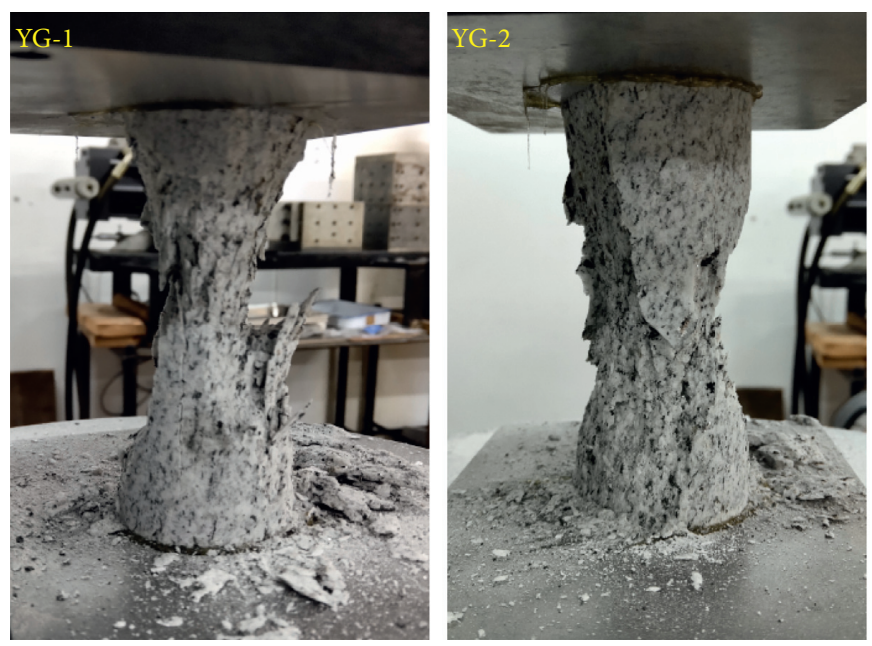

(b)
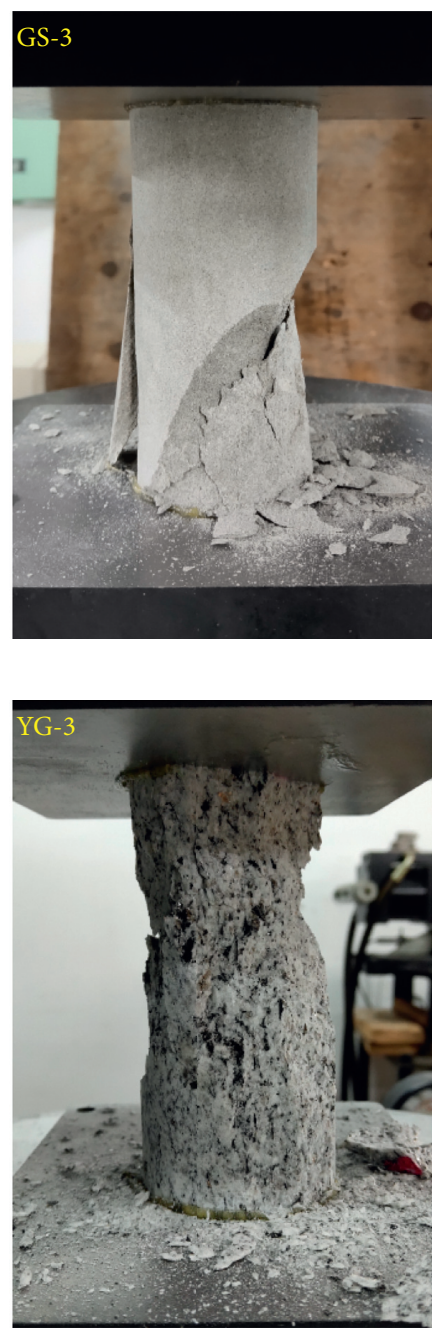

FIGURE 11: Failure modes of rock specimens in cyclic loading-unloading test: (a) Green sandstone; (b) Yueyang granite.

approach 2 can reduce the effect of cyclic loading on the calculation of total input energy by integrating the outermost loop loading curve. The obtained peak total input energy density should be closer to the results induced from the single loading-unloading tests. This can be proved by the calculation result of peak total input energy density for Green sandstone. However, the peak total input energy density result of Yueyang granite is not the same, which is due to the increase of the peak stress of Yueyang granite according to the stress-strain curves. Therefore, when the peak strengths of rocks under two test conditions are similar, we can conclude that the peak energy density values obtained by approach 2 in the cyclic loading-unloading test are closer to those obtained by single cyclic loading-unloading test.

\section{Discussion}

4.1. Failure and Ejection Performances of Rocks. Figure 11 shows the failure performances of Green sandstone and Yueyang granite in cyclic loading-unloading compression test. It can be observed that the obvious shear planes appeared on the specimen surface accompanied by axial splitting cracks when the rock failed. The failure modes of samples YG-1 and YG-2 are mainly shear failure, and the surface of the upper and lower biconical surfaces are split cracks. In general, the failure modes of both Green sandstone and Yueyang granite are shear-splitting composite failure, which is consistent with the failure mode of the rock specimens in the single cyclic loading-unloading test.

In the cyclic loading-unloading test, there are different degrees of ejection phenomena of Green sandstone and Yueyang granite when they failed, resulting in a large number of rock fragments and powders being distributed on the pressure head and the platform of test machine. From Figure 12, the volume and ejection distance of the fragments of Yueyang granite are larger than those of the Green sandstone. In addition, the ejection processes of rocks were record by high-speed camera. It can be seen that the ejection speed of Yueyang granite is higher than that of the Green sandstone. Meanwhile, the sound induced by Yueyang granite is stronger than that of the Green sandstone during 

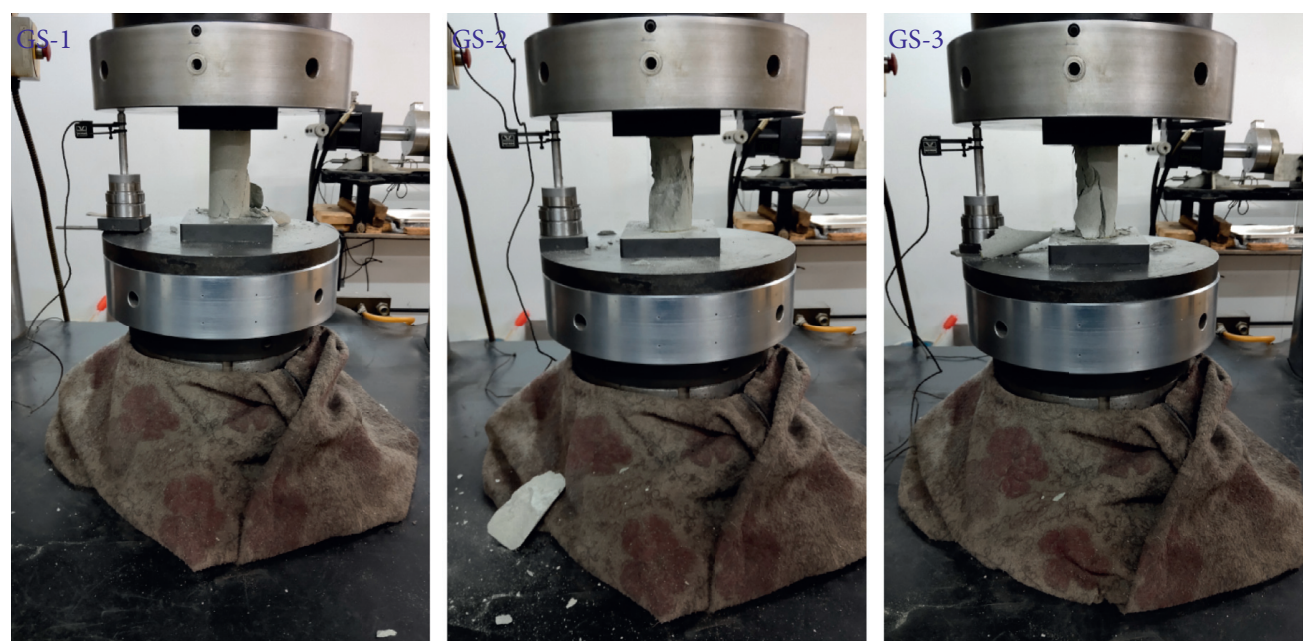

(a)
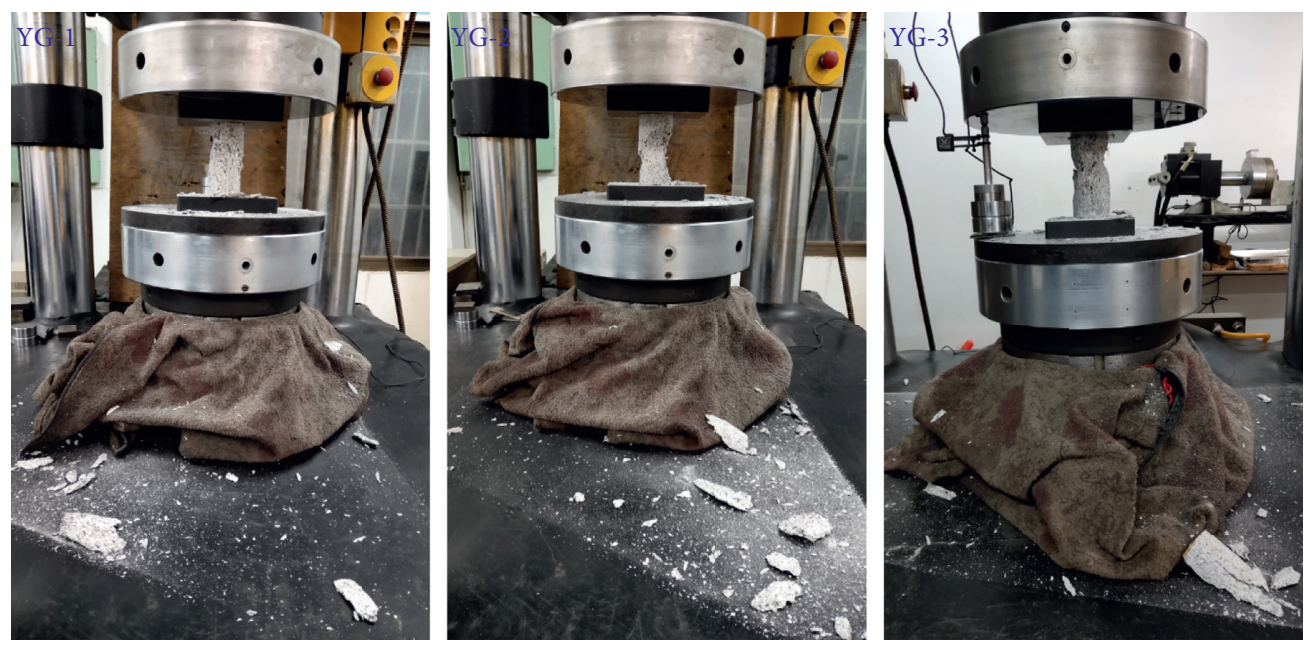

(b)

FIGURE 12: Ejection characteristics of rock specimens in cyclic loading-unloading test of (a) Green sandstone and (b) Yueyang granite.

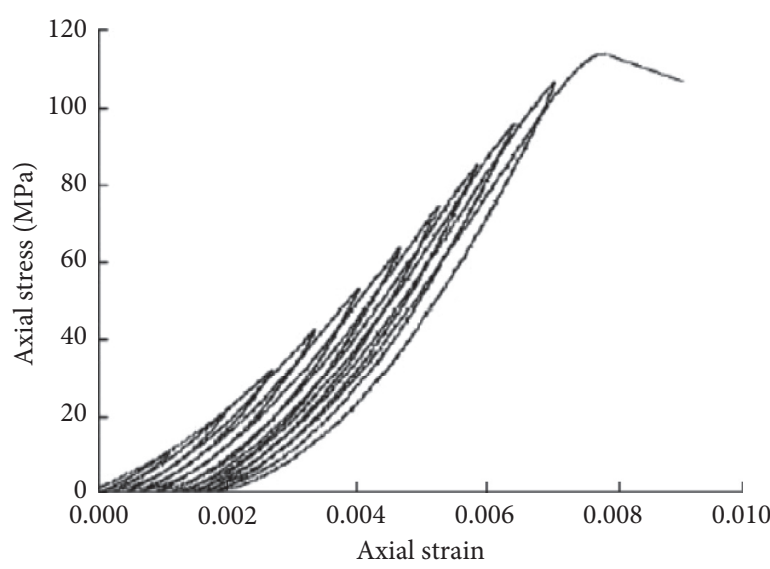

(a)

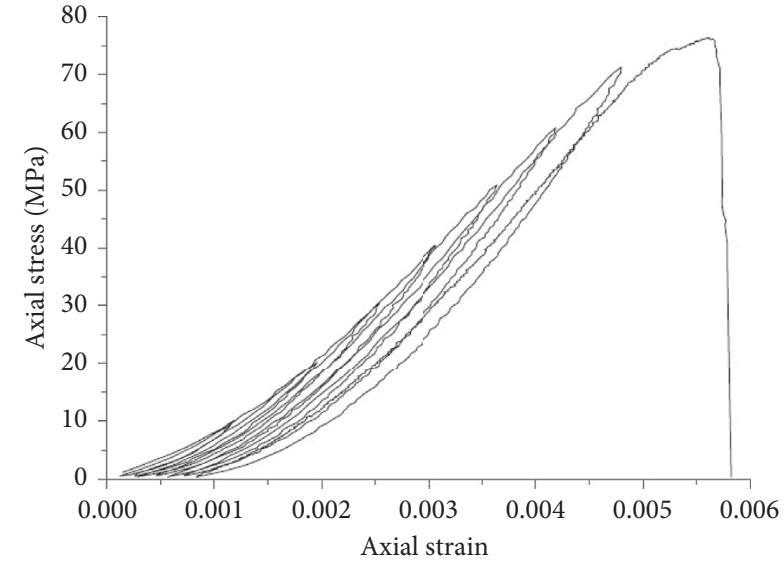

(b)

Figure 13: Stress-strain curves of typical specimen from (a) Zhang and Gao [23] and (b) Meng et al. [25]. 


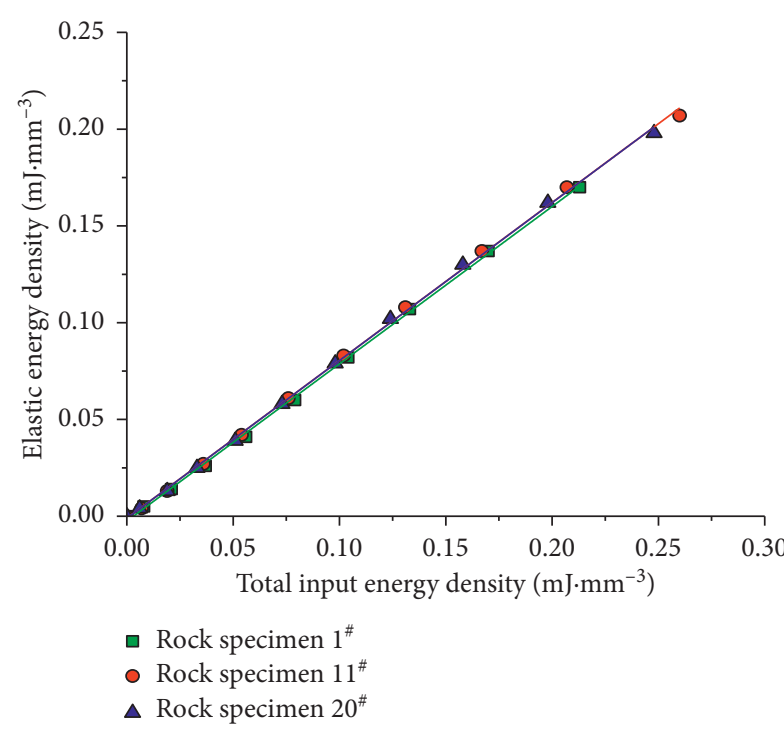

(a)

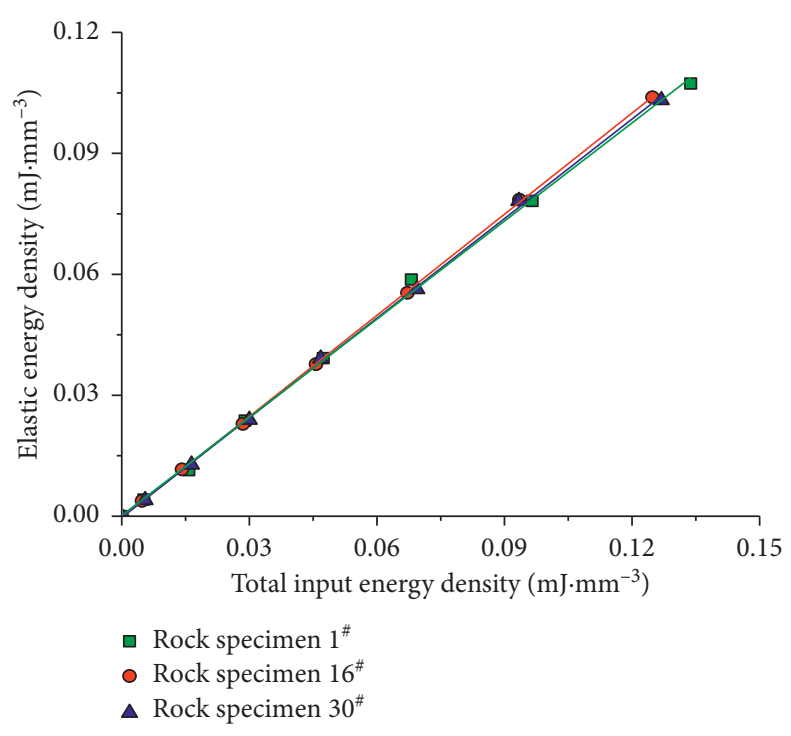

(b)

Figure 14: Relationship between the elastic and total input energy densities: (a) data from Zhang and Gao [23] and (b) Data from Meng et al. [25].

the failure process. From the ejection sound, speed, distance, and fragment volume during rock failure, it can be concluded that the ejection degree of Yueyang granite is greater than that of the Green sandstone. The ejection degrees of the rock specimens can reflect the bursting proneness grades of rock specimens; generally, the more violent the ejection are, the higher the rockburst proneness will be $[28,29]$.

Rockburst proneness is also closely related to the energy characteristics at the peak strength of rock, and many criteria for rockburst proneness were proposed considering the peak energy [29], such as the peak-strength strain energy storage index [28], the residual elastic energy index [34], and the potential peak-strength energy of elastic strain [29]. According to the peak energy density obtained by approach 1 (see Table 6), we can use the peak-strength strain energy storage index to judge the bursting proneness of Green sandstone and Yueyang granite. The calculated peakstrength strain energy storage indexes of Green sandstone and Yueyang granite are 3.04, 3.58, 3.57 and 9.25, 9.10, 8.00, respectively. With reference to the peak-strength strain energy storage index criterion, it was found that the Green sandstone and Yueyang granite have low and high rockburst proneness, respectively, which is consistent with the degrees of rock specimen ejection during failure. When the number of the specimens that can be used for the single cyclic loading-unloading test is insufficient, the peak-strength strain energy storage index of rocks can also be obtained by the cyclic loading-unloading test, and the similar rockburst proneness judgment results can be obtained.

4.2. Verification of the Linear Relationship between the Elastic and Total Input Energy Density. In order to further explore the reliability of the linear relationship between the elastic and total input energy densities of rocks, the test data from by Zhang and Gao [23] and Meng et al. [25] were used for verification. From the stress-strain curves (Figure 13) of the tested specimens, it can be seen that the cyclic loadingunloading test schemes in references $[23,25]$ are similar to those in this paper. From two references, three red sandstone specimens were selected, respectively, to verify the reliability of the linear relationship between the elastic and total input energy densities of rocks. The loading rates of specimens $1 \#, 11 \#$, and $20 \#$ from reference [21] were $1 \mathrm{kN} / \mathrm{s}$, $3 \mathrm{kN} / \mathrm{s}$, and $4 \mathrm{kN} / \mathrm{s}$, and those of specimens $1 \#, 16 \#$, and $30 \#$ from reference [23] were $0.5 \mathrm{kN} / \mathrm{s}, 2 \mathrm{kN} / \mathrm{s}$, and $4 \mathrm{kN} / \mathrm{s}$, respectively. The relationship between the elastic and total input energy densities of six red sandstone specimens in cyclic loading-unloading tests with different loading rates was obtained, as shown in Figure 14. It demonstrates that the elastic energy density increases linearly with the increase of total input energy density under different loading rates. Through the data fitting, the linear function and correlation coefficient $R^{2}$ between elastic and total input energy densities were obtained. The $R^{2}$ values of fitting functions for the specimen $1 \#, 11 \#$, and $20 \#$ from reference [21] are $0.9993,0.9993$, and 0.9994 , respectively, and those of the specimens 1\#, 16\#, and 30\# from reference [23] are $0.9985,0.9999$, and 0.9995 , respectively. The $R^{2}$ values of all the fitting functions are greater than 0.99 , indicating that a strong linear relationship between elastic and total input energy densities. From the above analysis, we can conclude that there is a linear relationship between the elastic and total input energy densities of rock, despite the rock type and loading rate.

\section{Conclusions}

Based on the uniaxial cyclic loading-unloading compression test, the energy evolution characteristics of Green sandstone and Yueyang granite were analyzed. And a new calculation 
method for energy storage coefficient of rock was proposed. The main conclusions are as follows:

(1) Under the single cyclic uniaxial loading-unloading test and uniaxial cyclic loading-unloading compression test, the maximum axial strains of rock materials are approximately equivalent. The change of peak strength of Green sandstone is very small. However, the peak strength of Yueyang granite obviously increased in the cyclic loading-unloading test.

(2) Two calculation approaches were proposed to calculate the total input energy density. The total input energy density of both rock materials increases nonlinear with the increase of stress level in the cyclic loading-unloading test. Whether the total input energy density is calculated by approach 1 or 2 , the variation law is very similar to that in the single uniaxial loading-unloading test. The variation law is also applicable to the elastic energy density and dissipated energy density. The elastic and dissipated energy densities increase linearly with the increasing of the total input energy density, which is independent of the calculation method for the total input energy density. In addition, the test data from by Zhang et al. [23] and Meng et al. [25] were also used to verify the reliability of the linear relationship between the elastic and total input energy densities. It is found that there is still a highly linear relationship between them. The ESC calculated by the approach 2 in cyclic loadingunloading test is closer to that obtained from the single cyclic loading-unloading test.

(3) The failure modes of Green sandstone and Yueyang granite are shear-splitting composite failure. From the ejection sound, speed, distance, and fragment volume of the rock specimens, it is observed that the ejection degree of Yueyang granite is greater than that of the Green sandstone. The peak-strength strain energy storage index was used to judge the rockburst proneness, and the results show that the Green sandstone and Yueyang granite have low and high rockburst proneness, respectively, which agrees with the degrees of specimen ejection during failure [34].

\section{Data Availability}

All data generated or analyzed during this study are included in this published article.

\section{Conflicts of Interest}

There are no conflicts of interest.

\section{Acknowledgments}

This work was supported by the National Natural Science Foundation of China (Grant no. 41877272) and Fundamental Research Funds for the Central Universities (Grant no. 2242020R10023).

\section{References}

[1] A. V. Mikhalyuk and V. V. Zakharov, "Dissipation of dynamic-loading energy in quasi-elastic deformation processes in rocks," Journal of Applied Mechanics and Technical Physics, vol. 38, no. 2, pp. 312-318, 1997.

[2] K. Bhattacharya, M. Ortiz, and G. Ravichandran, "Energybased model of compressive splitting in heterogeneous brittle solids," Journal of the Mechanics and Physics of Solids, vol. 46, no. 10, pp. 2171-2181, 1998.

[3] D. Huang and Y. R. Li, "Conversion of strain energy in triaxial unloading tests on marble," International Journal of Rock Mechanics and Mining Sciences, vol. 66, no. 1, pp. 160-168, 2014.

[4] P. L. P. Wasantha, P. G. Ranjith, and S. S. Shao, "Energy monitoring and analysis during deformation of beddedsandstone: use of acoustic emission," Ultrasonics, vol. 54, no. 1, pp. 217-226, 2014.

[5] Y. Deng, M. Chen, Y. Jin, and D. Zou, "Theoretical analysis and experimental research on the energy dissipation of rock crushing based on fractal theory," Journal of Natural Gas Science and Engineering, vol. 33, pp. 231-239, 2016.

[6] V. Bratov and Y. Petrov, "Optimizing energy input for fracture by analysis of the energy required to initiate dynamic mode I crack growth," International Journal of Solids and Structures, vol. 44, no. 7-8, pp. 2371-2380, 2007.

[7] F. Q. Gong, S. Luo, and J. Y. Yan, "Energy storage and dissipation evolution process and characteristics of marble in three tension-type failure tests," Rock Mechanics and Rock Engineering, vol. 51, no. 11, pp. 3613-3624, 2018.

[8] F. Q. Gong, Y. J. Yan, S. Luo, and X. B. Li, "Investigation on the linear energy storage and dissipation laws of rock materials under uniaxial compression," Rock Mechanics and Rock Engineering, vol. 52, no. 12, pp. 4237-4255, 2019.

[9] S. Luo and F. Q. Gong, "Linear energy storage and dissipation laws of rocks under preset angle shear conditions," Rock Mechanics and Rock Engineering, vol. 53, no. 7, pp. 3303$3323,2020$.

[10] X. J. Hao, L. Yuan, J. H. Xue et al., "Physical model test and evaluation for the tunnel stability influenced by magnitude and path of loading," Journal of Testing and Evaluation, vol. 48, no. 2, Article ID 20170690, 2020.

[11] H. P. Song, H. Zhang, D. H. Fu, and Q. Zhang, "Experimental analysis and characterization of damage evolution in rock under cyclic loading," International Journal of Rock Mechanics and Mining Sciences, vol. 88, pp. 157-164, 2016.

[12] M. V. M. S. Rao and Y. V. Ramana, "A study of progressive failure of rock under cyclic loading by ultrasonic and ae monitoring techniques," Rock Mechanics and Rock Engineering, vol. 25, no. 4, pp. 237-251, 1992.

[13] M. K. Jafari, F. Pellet, M. Boulon, and K. A. Hosseini, "Experimental study of mechanical behaviour of rock joints under cyclic loading," Rock Mechanics and Rock Engineering, vol. 37, no. 1, pp. 3-23, 2004.

[14] A. M. Ferrero, M. Migliazza, and G. Tebaldi, "Development of a new experimental apparatus for the study of the mechanical behaviour of a rock discontinuity under monotonic and cyclic loads," Rock Mechanics and Rock Engineering, vol. 43, no. 6, pp. 685-695, 2010.

[15] A. Fathi, Z. Moradian, P. Rivard, and G. Ballivy, "Shear mechanism of rock joints under pre-peak cyclic loading condition," International Journal of Rock Mechanics and Mining Sciences, vol. 83, pp. 197-210, 2016. 
[16] S. K. Ray, M. Sarkar, and T. N. Singh, "Effect of cyclic loading and strain rate on the mechanical behaviour of sandstone," International Journal of Rock Mechanics and Mining Sciences, vol. 36, no. 4, pp. 543-549, 1999.

[17] X. S. Liu, J. G. Ning, Y. L. Tan, and Q. H. Gu, "Damage constitutive model based on energy dissipation for intact rock subjected to cyclic loading," International Journal of Rock Mechanics and Mining Sciences, vol. 85, no. 1, pp. 27-32, 2016.

[18] R. Geranmayeh Vaneghi, B. Ferdosi, A. D. Okoth, and B. Kuek, "Strength degradation of sandstone and granodiorite under uniaxial cyclic loading," Journal of Rock Mechanics and Geotechnical Engineering, vol. 10, no. 1, pp. 117-126, 2018.

[19] E. L. Liu and S. M. He, "Effects of cyclic dynamic loading on the mechanical properties of intact rock samples under confining pressure conditions," Engineering Geology, vol. 125, pp. 81-91, 2012.

[20] M. N. Bagde and V. Petroš, "Fatigue and dynamic energy behaviour of rock subjected to cyclical loading," International Journal of Rock Mechanics and Mining Sciences, vol. 46, no. 1, pp. 200-209, 2009.

[21] D. Z. Song, E. Y. Wang, and J. Liu, "Relationship between EMR and dissipated energy of coal rock mass during cyclic loading process," Safety Science, vol. 50, no. 4, pp. 751-760, 2012.

[22] Z. Z. Zhang and F. Gao, "Experimental research on energy evolution of red sandstone samples under uniaxial compression," Chinese Journal of Rock Mechanics and Engineering, vol. 31, no. 5, pp. 953-962, 2012.

[23] Z. Z. Zhang and F. Gao, "Experimental investigation on the energy evolution of dry and water-saturated red sandstones," International Journal of Mining Science and Technology, vol. 25, no. 3, pp. 383-388, 2015.

[24] Q. B. Meng, M. W. Zhang, L. J. Han, H. Pu, and T. Y. Nie, "Effects of acoustic emission and energy evolution of rock specimens under the uniaxial cyclic loading and unloading compression," Rock Mechanics and Rock Engineering, vol. 49, no. 10, pp. 3873-3886, 2016.

[25] Q. B. Meng, M. W. Zhang, L. J. Han, H. Pu, and Y. L. Chen, "Acoustic emission characteristics of red sandstone specimens under uniaxial cyclic loading and unloading compression," Rock Mechanics and Rock Engineering, vol. 51, no. 4, pp. 969-988, 2018.

[26] H. Munoz, A. Taheri, and E. K. Chanda, "Rock drilling performance evaluation by an energy dissipation based rock brittleness index," Rock Mechanics and Rock Engineering, vol. 49, no. 8, pp. 3343-3355, 2016.

[27] H. Munoz, A. Taheri, and E. K. Chanda, "Fracture energybased brittleness index development and brittleness quantification by pre-peak strength parameters in rock uniaxial compression," Rock Mechanics and Rock Engineering, vol. 49, no. 12 , pp. $4587-4606,2016$.

[28] F. Q. Gong, J. Y. Yan, X. B. Li, and S. Luo, "A peak-strength strain energy storage index for rock burst proneness of rock materials," International Journal of Rock Mechanics and Mining Sciences, vol. 117, pp. 76-89, 2019.

[29] F. Q. Gong, Y. L. Wang, and S. Luo, "Rockburst proneness criteria for rock materials: review and comprehensive comparison," Journal of Central South University, vol. 27, no. 10, 2020.

[30] H. P. Xie, L. Y. Li, R. D. Peng, and Y. Ju, "Energy analysis and criteria for structural failure of rocks," Journal of Rock Mechanics and Geotechnical Engineering, vol. 1, no. 1, pp. 11-20, 2009.
[31] B. G. Tarasov and T. R. Stacey, "Features of the energy balance and fragmentation mechanisms at spontaneous failure of class I and class II rocks," Rock Mechanics and Rock Engineering, vol. 50, no. 10, pp. 2563-2584, 2017.

[32] M. M. He, B. Q. Huang, C. H. Zhu, Y. S. Chen, and N. Li, "Energy dissipation-based method for fatigue life prediction of rock salt," Rock Mechanics and Rock Engineering, vol. 51, no. 5, pp. 1447-1455, 2018.

[33] F. Q. Gong and J. Hu, "Energy dissipation characteristic of red sandstone in the dynamic Brazilian disc test with SHPB setup," Advances in Civil Engineering, vol. 2020, Article ID 7160937, 10 pages, 2020.

[34] F. Q. Gong, J. Y. Yan, and X. B. Li, "A new criterion of rock burst proneness based on the linear energy storage law and the residual elastic energy index," Chinese Journal of Rock Mechanics and Engineering, vol. 37, no. 9, pp. 1993-2014, 2019. 